\title{
Role of the Coronary Sinus in Maintenance of Atrial Fibrillation
}

\author{
HAKAN ORAL, M.D., MEHMET OZAYDIN, M.D., AMAN CHUGH, M.D., \\ CHRISTOPH SCHARF, M.D., HIROSHI TADA, M.D., BURR HALL, M.D., \\ PETER CHEUNG, M.D., FRANK PELOSI, JR., M.D., BRADLEY P. KNIGHT, M.D., \\ and FRED MORADY, M.D.
}

From the Division of Cardiology, Department of Internal Medicine, University of Michigan, Ann Arbor, Michigan, USA

\begin{abstract}
Coronary Sinus and Atrial Fibrillation. Introduction: Bursts of tachycardia arising in the pulmonary veins may play an important role in perpetuating atrial fibrillation (AF). However, the role of the coronary sinus (CS) in the perpetuation of AF has been unclear. The aim of this study was to determine whether the CS plays a role in perpetuation of AF.

Methods and Results: Pulmonary vein isolation was performed by segmental ostial ablation with radiofrequency energy in 22 consecutive patients with paroxysmal AF. Bipolar and unipolar electrograms recorded in the left atrium and CS were analyzed during atrial pacing from the mitral annulus and during AF. There was a mean of $2.5 \pm 0.5$ electrical connections between the CS and the left atrium. The electrical connections between the left atrium and CS were ablated with a mean of $6.2 \pm 2.7$ minutes of radiofrequency energy applied along the atrial side of the inferior mitral annulus. During AF, episodes of intermittent tachycardia alternated between the left atrium and the CS. Among the 22 patients, sustained AF was still inducible in 9 after pulmonary vein isolation. After electrical disconnection of the CS from the left atrium, sustained AF was inducible in only 3 of these 9 patients.

Conclusion: The CS may be a source of rapid repetitive electrical activity during AF. The lower probability of inducible sustained AF after electrical disconnection of the CS from the left atrium suggests that the CS may play a role in perpetuating AF. (J Cardiovasc Electrophysiol, Vol. 14, pp. 1329-1336, December 2003)
\end{abstract}

coronary sinus, atrial fibrillation, catheter ablation

\section{Introduction}

Muscle sleeves surrounding the pulmonary veins have been found to generate rapid electrical activity that may play a role in perpetuating atrial fibrillation (AF). ${ }^{1,2}$ The coronary sinus (CS) also is covered with a myocardial sleeve, and muscular connections between this muscle sleeve and the left atrium have been demonstrated anatomically. ${ }^{3-6}$ Focal atrial tachycardias originating in the musculature of the CS have been reported, ${ }^{7,8}$ and the $\mathrm{CS}$ musculature may participate in a macroreentrant circuit that generates left atrial flutter. ${ }^{9}$ Moreover, a recent study demonstrated that double potentials are recorded in the CS more often in patients with paroxysmal $\mathrm{AF}$ than in other patients and suggested that the CS may serve as a substrate for $\mathrm{AF} .^{10}$

The aim of this study was to investigate whether the CS plays a role in the perpetuation of AF. This was accomplished by assessing the AF cycle length within the CS and the inducibility of sustained AF after pulmonary vein isolation, before and after electrical disconnection of the CS from the left atrium.

Supported by the Ellen and Robert Thompson Atrial Fibrillation Research Fund.

Address for correspondence: Hakan Oral, M.D., Division of Cardiology, Department of Internal Medicine, University of Michigan, 1500 E. Medical Center Drive, Ann Arbor, MI 48109-0311. Fax: 734-936-7026; E-mail: oralh@umich.edu

Manuscript received 30 April 2003; Accepted for publication 25 August 2003.

doi: $10.1046 / j .1540-8167.2003 .03222 . x$
Methods

\section{Study Subjects}

The subjects of this study were 22 consecutive patients (19 men and 3 women; mean age $47 \pm 12$ years) who underwent an electrophysiologic procedure for treatment of paroxysmal AF. AF was first diagnosed $6 \pm 5$ years prior to the procedure. None of the 22 patients had structural heart disease. Mean left ventricular ejection fraction and left atrial diameter were $0.56 \pm 0.04 \mathrm{~mm}$ and $39 \pm 6 \mathrm{~mm}$, respectively.

\section{Electrophysiologic Study}

All patients provided written informed consent. A decapolar electrode catheter (Daig Corp., Minnetonka, MN, USA) with 2-5-2-5-2-5-2-5-2 $\mathrm{mm}$ interelectrode spacing was positioned in the CS such that the proximal electrode pair was just inside the CS ostium. Transseptal catheterization was performed and systemic anticoagulation was achieved to maintain an activated clotting time of 250 to $350 \mathrm{sec}-$ onds. Venograms of the pulmonary veins were obtained. A deflectable decapolar catheter with a distal ring configuration (Lasso ${ }^{\mathrm{TM}}$ catheter, Biosense Webster, Diamond Bar, CA, USA) was used for ostial mapping. A deflectable, quadripolar 7-French catheter with 2-5-2 $\mathrm{mm}$ interelectrode spacing and a 4-mm distal electrode with an embedded thermistor (EP Technologies, Inc., Mountain View, CA, USA) was used for mapping and ablation. Bipolar and unipolar electrograms were filtered at bandpass settings of 30 to $500 \mathrm{~Hz}$ and 0.5 to $200 \mathrm{~Hz}$, respectively, and were recorded digitally (EPMed Systems, Inc., West Berlin, NJ, USA). Electrograms were recorded from the CS catheter and the mapping catheter positioned along the inferior mitral annulus. 


\section{Pulmonary Vein Isolation}

Pulmonary vein isolation was performed by segmental ostial ablation with conventional applications of radiofrequency energy, guided by pulmonary vein potentials, as described previously. ${ }^{11,12}$ The left superior, left inferior, and right superior pulmonary veins were targeted in all patients. The right inferior pulmonary vein was targeted in 17 of the 22 patients. Applications of radiofrequency energy were delivered at a maximum of $35 \mathrm{~W}$, with a target temperature of $52^{\circ} \mathrm{C}$ and duration up to 40 seconds. Elimination of all ostial pulmonary vein potentials and complete entrance block into the pulmonary vein were the endpoints of ostial ablation..$^{11,12}$

\section{Study Protocol}

Among the 22 patients, 12 were in AF upon entry into the electrophysiology laboratory. In the other patients, $\mathrm{AF}$ was induced by 5 - to 10 -second bursts of atrial pacing at cycle lengths of 200 to $180 \mathrm{~ms}$. Pacing was performed from a quadripolar catheter positioned within the CS. For the purposes of this study, an episode of induced AF that lasted $>5$ minutes was considered sustained. After pulmonary vein isolation, atrial pacing again was performed five times at cycle lengths of 200 to $180 \mathrm{~ms}$, to assess the inducibility of sustained AF. Whenever AF was inducible, electrograms recorded in the CS and in the left atrium were digitally recorded for post hoc analysis. In patients with inducible sustained AF after pulmonary vein isolation, sinus rhythm was restored by transthoracic cardioversion after approximately 10 minutes.

In this study for the description of electrical connections between the CS and the left atrium, attitudinally correct nomenclature was used. ${ }^{13,14}$ When accurately described, mitral annular sites commonly referred as lateral are posterior, posterior are inferior, anterior are superior, and medial are paraseptal. ${ }^{13,14}$

To identify electrical connections between the CS and the left atrium, the mapping catheter was positioned along the inferior mitral valvular annulus and atrial pacing was performed at twice threshold with this catheter. Pacing was first performed near the posterior annulus, adjacent to electrode 1 (distal) of the decapolar CS catheter. The mapping catheter then was sequentially positioned along the annulus at sites that were adjacent to other electrodes of the decapolar CS catheter, and pacing was repeated at these sites (Fig. 1).

Analysis of CS potentials was based on the unipolar electrograms recorded within the CS. When double potentials were present, the first component was considered a far-field potential attributable to left atrial activation, and the second component was considered a near-field potential with a rapid intrinsic deflection indicative of local CS activation (Fig. 2). Sites of earliest local CS activation during pacing at the mitral annulus were considered to be sites of electrical connections between the left atrium and the CS. A change in the CS activation sequence during atrial pacing from different mitral annular sites was considered indicative of multiple connections (Fig. 3). An electrical connection localized to one electrode was defined as a discrete connection, whereas a connection that spanned $\geq 2$ electrodes was defined as a broad or nondiscrete connection.

Conventional applications of radiofrequency energy were delivered at sites along the inferior mitral valve annulus where there was evidence of an electrical connection. The applications were 30 seconds in duration, with a target temperature of $60^{\circ} \mathrm{C}$ and maximum power of $50 \mathrm{~W}$. A change in the activation sequence of unipolar electrograms recorded within the CS during atrial pacing along the mitral annulus was considered indicative of successful ablation of an electrical
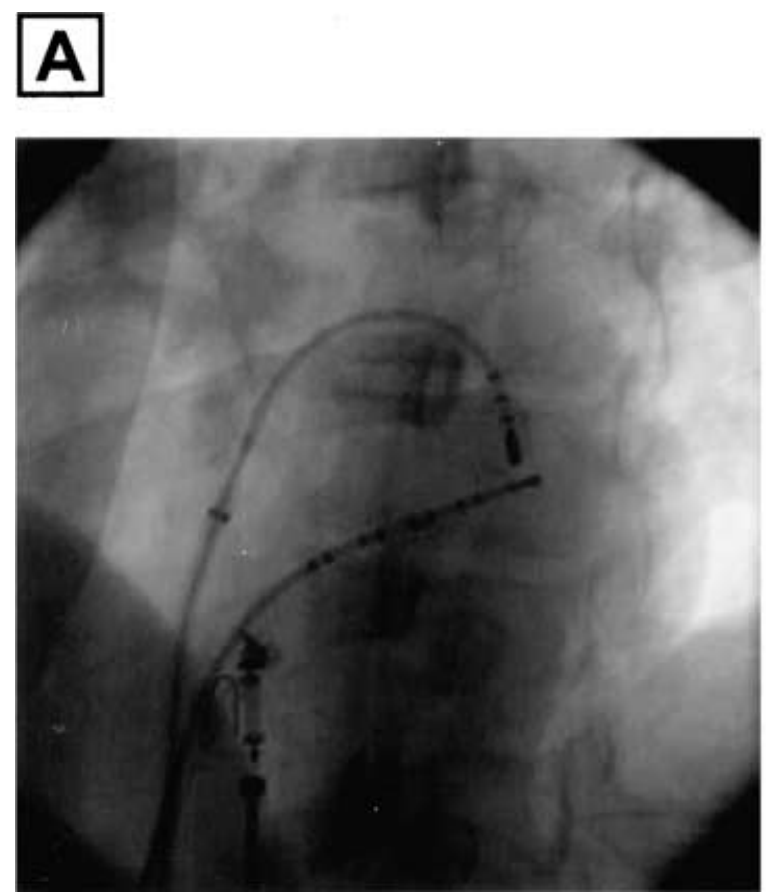
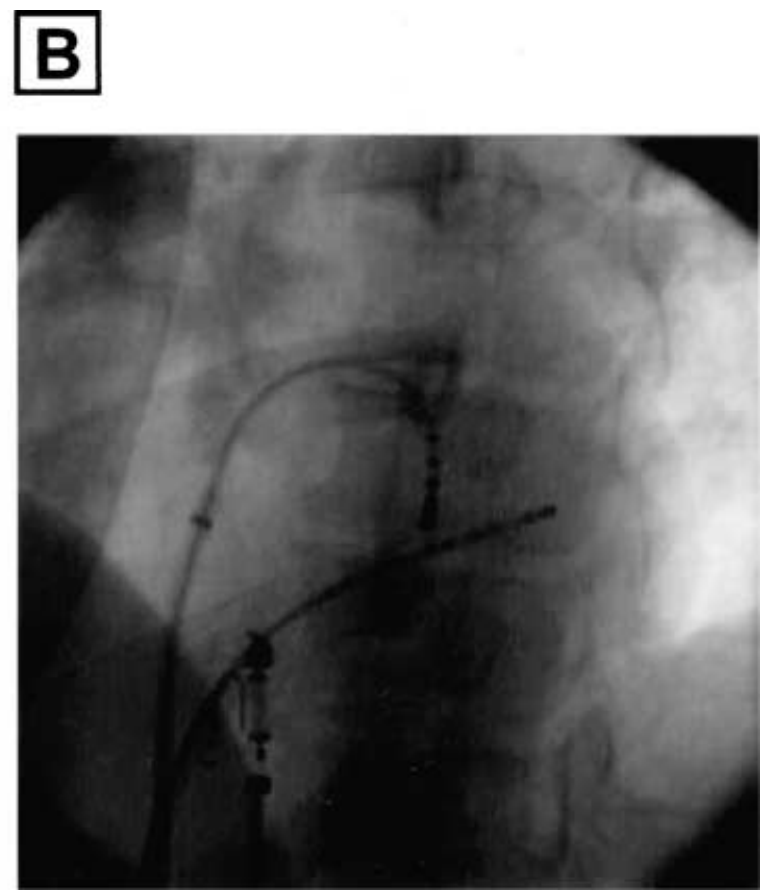

Figure 1. Fluoroscopic image of catheter positions in the $45^{\circ}$ left anterior oblique view. A decapolar catheter is positioned in the coronary sinus. Shown are examples of the mapping/ablation catheter within the left atrium positioned along the mitral valve annulus adjacent to electrode $2(A)$ and electrode $6(B)$. 


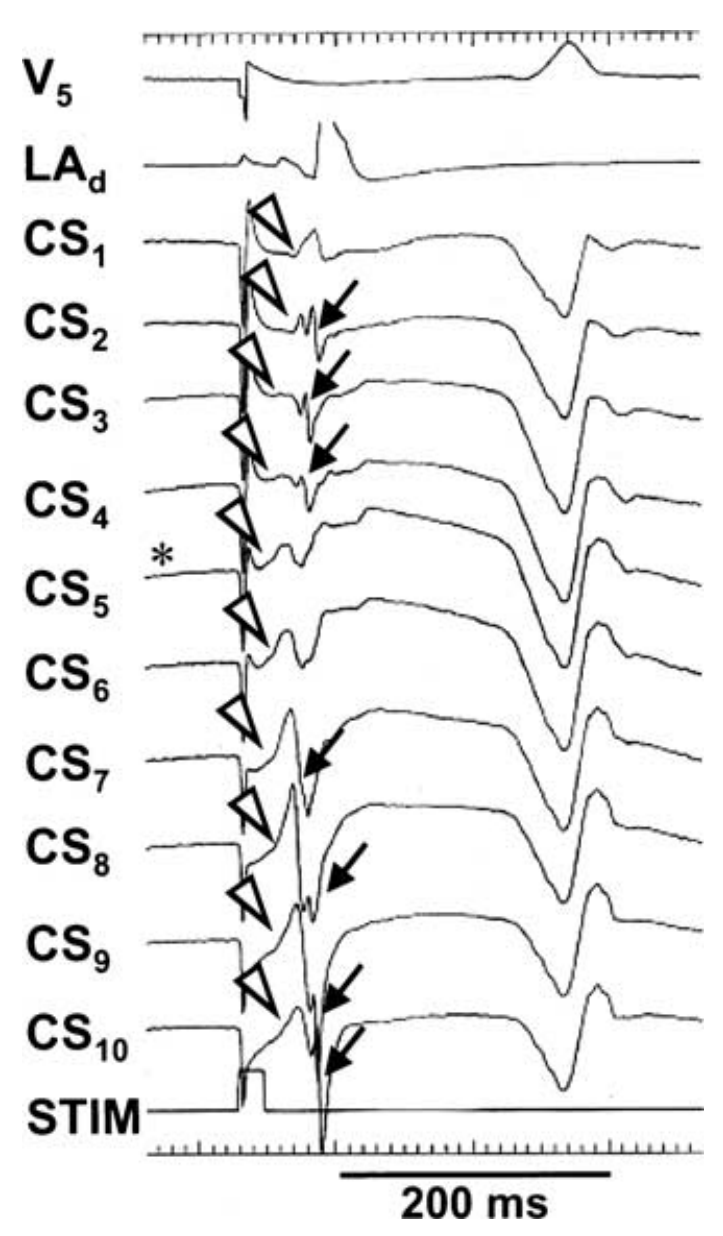

Figure 2. Unipolar electrograms recorded by a decapolar catheter within the coronary sinus (CS). In this figure and in following figures, the most proximal electrode $\left(\mathrm{CS}_{10}\right)$ was positioned at the ostium of the CS. The unipolar electrograms were recorded during pacing from the inferior mitral valve annulus, adjacent to electrode 5 (asterisk) of the decapolar catheter. Double potentials are recorded by most of the electrodes: the first component is a far-field potential attributable to left atrial activation (open arrowheads), and the second component has a rapid intrinsic deflection and represents local CS activation (closed arrows). The earliest CS potential is recorded at $\mathrm{CS}_{7}$, indicating the presence of a coronary sinus-left atrial connection adjacent to $\mathrm{CS}_{7} . \mathrm{LA}_{d}=$ left atrial distal; Stim $=$ stimulus channel.

connection between the CS and the left atrium. After ablation of all identifiable electrical connections between the CS and the left atrium, rapid atrial pacing was again performed in the same manner as before ablation in all patients to determine whether sustained AF was still inducible. The total number of individual ablation sites that resulted in a change in the activation sequence within the CS was considered to indicate the number of electrical connections.

\section{Analysis of Electrograms Recorded Within the CS}

During AF, bipolar electrograms in the CS and the left atrium were recorded for at least 30 seconds and manually analyzed off-line to determine the AF cycle lengths. To account for fractionation and slow and fibrillatory conduction, only electrograms with an amplitude $>10 \%$ of the maximum electrogram amplitude and separated by at least $50 \mathrm{~ms}$ were analyzed. Rapid electrical activity ${ }^{1,2,15-17}$ within the CS was defined as a burst of electrical activity that had a cycle length shorter than in the adjacent left atrium (Fig. 4). Conversely, rapid electrical activity in the left atrium was defined as a burst of electrical activity that had a cycle length shorter than in the adjacent CS. To measure cycle lengths, electrograms recorded with the distal bipole of the mapping catheter positioned at the inferior mitral annulus and with the bipole of the CS catheter adjacent to the mapping catheter were analyzed.

\section{Analysis of P Waves Before and After Disconnection of CS from Left Atrium}

To determine the effect of CS disconnection from the left atrium on global atrial activation, the duration of the $P$ wave recorded in lead II was measured using electronic calipers before and after CS disconnection.

\section{Follow-Up}

All patients were seen in an outpatient clinic 4 to 6 weeks after the ablation procedure and every 3 months thereafter. Patients who reported symptoms were provided with an event recorder to document the nature of these episodes. No patient was lost to follow-up.

\section{Statistical Analysis}

Continuous variables are expressed as mean $\pm 1 \mathrm{SD}$ and were compared with a paired $t$-test. Categorical variables were compared by Chi-square analysis or with the Fisher's exact test. $\mathrm{P}<0.05$ was considered statistically significant.

\section{Results}

\section{Pulmonary Vein Isolation}

Among the 83 targeted pulmonary veins, 82 (99\%) were successfully electrically isolated.

\section{Inducibility of AF Before Disconnection of the CS}

Before pulmonary vein isolation, sustained AF was inducible in all patients. After successful isolation of the pulmonary veins, sustained AF was still inducible in $9(41 \%)$ of the 22 patients. In these 9 patients, the mean duration of episodes of sustained AF before transthoracic cardioversion was $11.9 \pm 5.7$ minutes. In the other 13 patients, inducible AF spontaneously converted to sinus rhythm in a mean of 1.1 \pm 1.2 minutes (range $1 \mathrm{~s}$ to $3.8 \mathrm{~min}$ ).

\section{Electrical Connections Between Left Atrium and CS}

A CS potential was recorded at a mean of $9 \pm 1$ electrodes of the decapolar catheter positioned within the CS. There was a mean of $2.5 \pm 0.5$ electrical connections between the CS and the left atrium. Among the 47 connections, 17 (36\%) were located at the posterior or inferoposterior part of the mural aspect of the mitral annulus, $16(34 \%)$ were located at the inferior portion of the mural aspect of the mitral annulus, and the remaining $14(30 \%)$ were located at the paraseptal portion of the mural aspect of the mitral annulus. Among the 47 electrical connections, 17 (36\%) spanned $\geq 2$ contiguous electrodes $(\geq 5 \mathrm{~mm})$, and the remaining were discrete connections localized to 1 electrode $(2 \mathrm{~mm})$. 

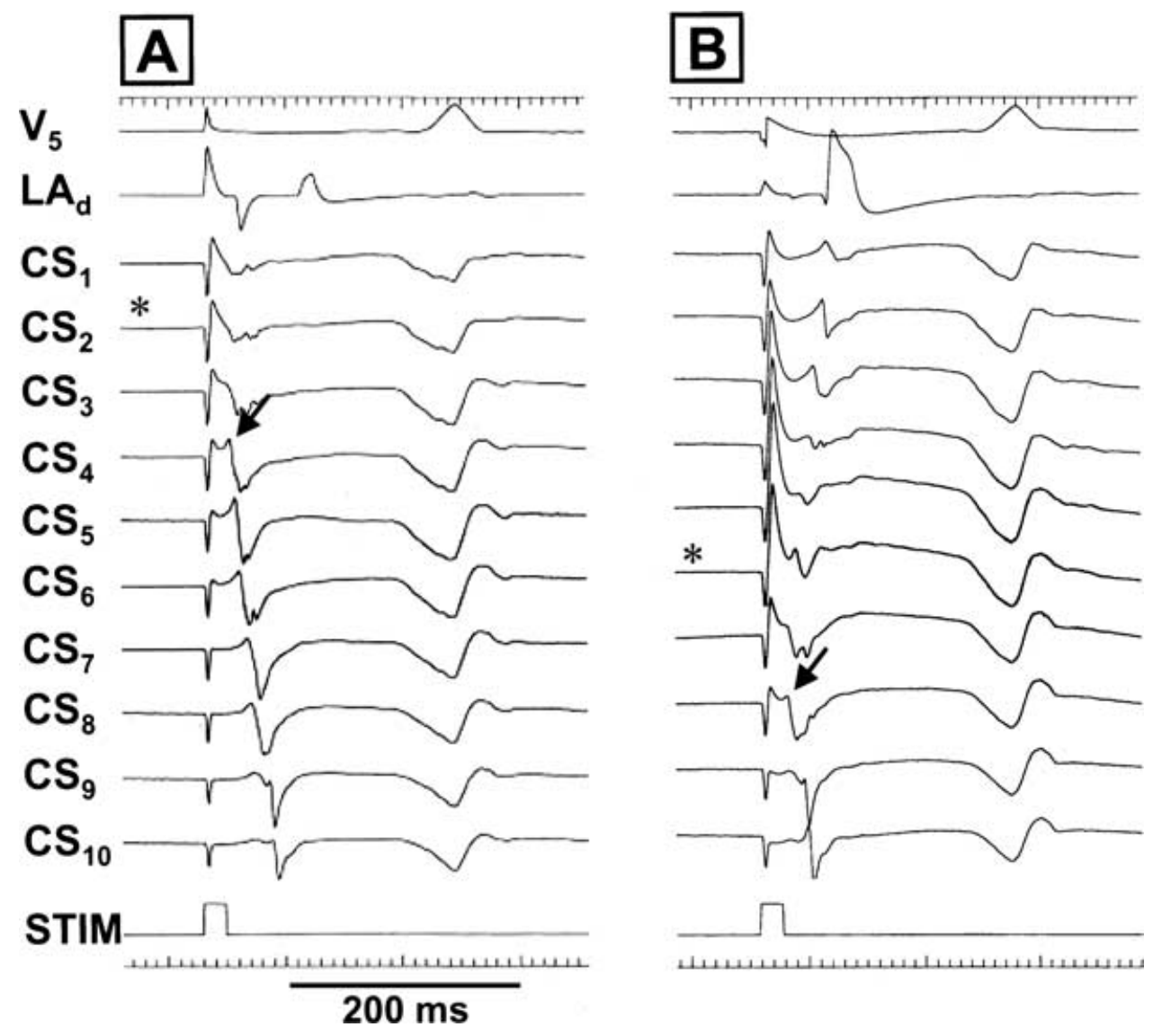

Figure 3. Example of multiple connections between the coronary sinus (CS) and the left atrium. $L A_{d}=$ left atrial distal; $L A_{p}=$ left atrial proximal; Stim $=$ stimulus channel. A: Activation sequence within the CS during pacing from the posterior mitral valve annulus, adjacent to electrode 2 (asterisk) of the CS catheter. Note that earliest activation of the CS (arrow) is recorded at electrode 4 of the decapolar catheter. B: When pacing was performed from the inferior annulus adjacent to electrode 6 (asterisk), there was a change in the activation sequence within the CS. Earliest activation within the CS (arrow) shifted to electrode 8. This is evidence of at least two electrical connections between the left atrium and CS.

\section{AF Cycle Length in CS and Left Atrium Before Disconnection of CS from Left Atrium}

After pulmonary vein isolation, there was a mean of $4 \pm$ 3 episodes per minute of rapid electrical activity in the left atrium; the mean duration of these episodes was $1,173 \pm$ $420 \mathrm{~ms}$, and their mean cycle length was $93 \pm 19 \mathrm{~ms}$, which was significantly shorter than the simultaneous cycle length in the CS $(153 \pm 42 \mathrm{~ms}, \mathrm{P}<0.001)$. In $17(78 \%)$ of the 22 patients, there also was a mean of $19 \pm 8$ episodes of rapid electrical activity within the CS; the mean duration of these episodes was 1,471 $\pm 451 \mathrm{~ms}$, and their mean cycle length was $83 \pm 20 \mathrm{~ms}$, which was significantly shorter than the simultaneous cycle length in the left atrium $(177 \pm 36 \mathrm{~ms}, \mathrm{P}$ $<0.001)$.

\section{Electrical Disconnection of the CS from the Left Atrium}

Electrical disconnection of the CS was achieved with $11 \pm$ 3 applications of radiofrequency energy that had a cumulative duration of $6.2 \pm 2.7$ minutes (Fig. 5). There were no complications related to catheter ablation in any of the patients.

Before electrical disconnection of the CS, a CS potential was recorded within the CS by a mean of $9 \pm 1$ electrodes of the decapolar catheter. After electrical disconnection of the CS from the left atrium, the number of CS electrodes at which a CS potential was recorded decreased to a mean of
$3 \pm 1$ electrodes $(\mathrm{P}<0.01)$ in 17 of the 22 patients. In the remaining 5 patients, no residual CS potentials were recorded within the CS after electrical disconnection of the CS from the left atrium.

When residual CS potentials were present after electrical disconnection of the CS, the stimulus to CS potential interval during atrial pacing along the mitral annulus increased from $30 \pm 8 \mathrm{~ms}$ before ablation to $59 \pm 9 \mathrm{~ms}$ after ablation $(\mathrm{P}<0.001)$. Among 55 residual CS potentials, 26 (47\%) were recorded in the proximal position of the CS by the electrodes closest to the ostium (Fig. 5).

\section{Inducibility of AF After Disconnection of the CS}

Among the 9 patients who had inducible sustained AF after isolation of the pulmonary veins, sustained AF was still inducible in only 3 after electrical disconnection of the CS from the left atrium ( $\mathrm{P}=0.04$, Fig. 6).

\section{Cycle Lengths Within the CS Before and After Electrical Disconnection}

In patients who still had inducible AF after CS disconnection, regardless of whether the episode was sustained or nonsustained, there were fewer episodes of rapid electrical activity within the CS ( $3 \pm 3$ per minute) than before CS disconnection $(19 \pm 8$ per minute, $\mathrm{P}<0.001)$. During these episodes of rapid electrical activity, the cycle length recorded 

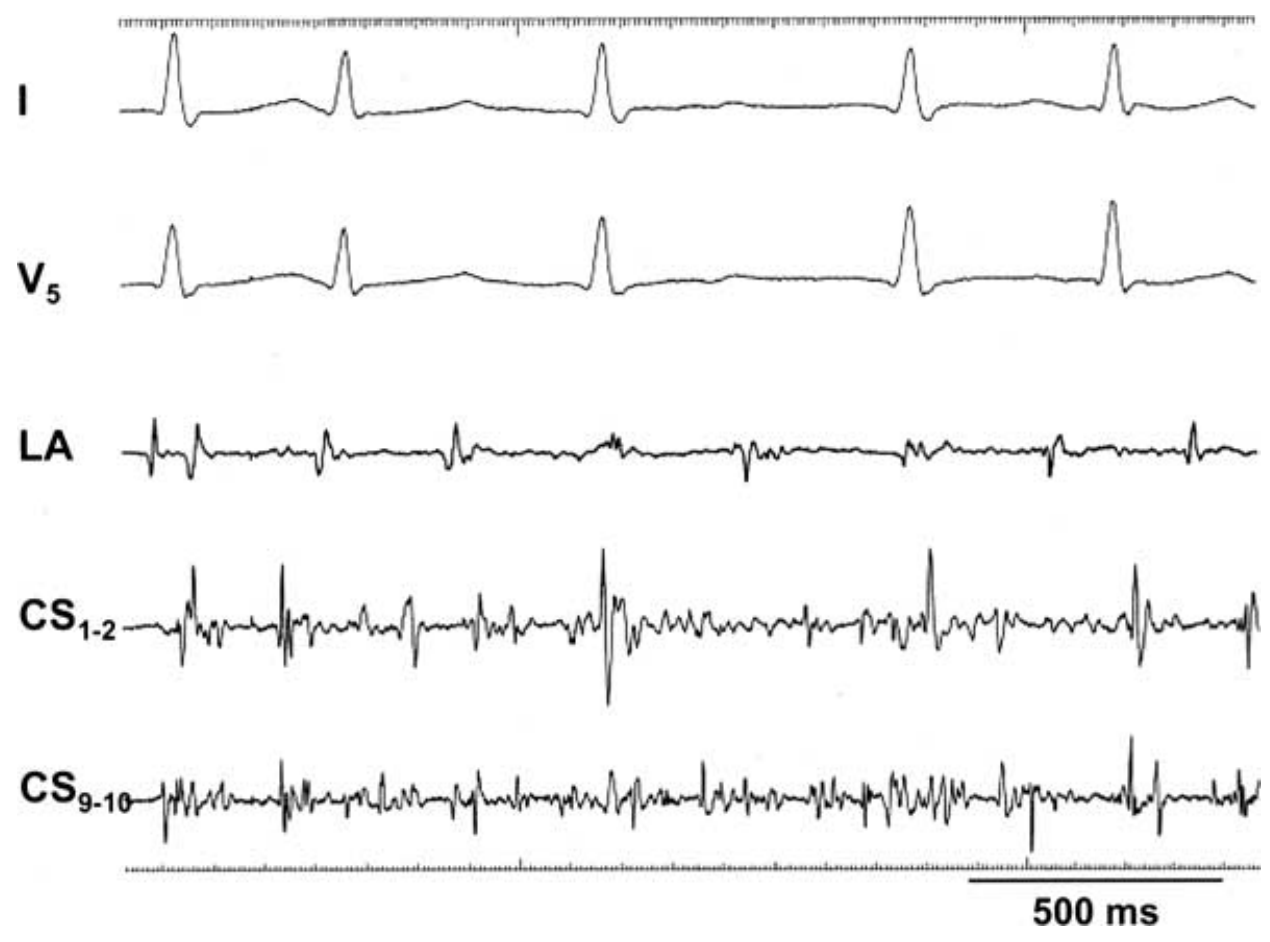

Figure 4. Example of rapid electrical activity within the coronary sinus (CS). All electrograms are bipolar recordings. $C S_{1-2}$ was positioned adjacent to the posterior mitral annulus, and CS9-10 was positioned at the ostium of the CS. There is rapid electrical activity within the CS that has a mean cycle length of $95 \mathrm{~ms}$, which is shorter than the mean atrial cycle length of $220 \mathrm{~ms}$ in the left atrium (LA), adjacent to CS9-10.

within the CS was longer after than before electrical disconnection of the CS $(133 \pm 34 \mathrm{~ms}$ vs $84 \pm 23 \mathrm{~ms}$, respectively, $\mathrm{P}<0.01)$.

\section{P Wave Duration}

After disconnection of the CS from the left atrium, the $\mathrm{P}$ wave duration in lead II increased from a baseline value of $117 \pm 27 \mathrm{~ms}$ to $129 \pm 20 \mathrm{~ms}(\mathrm{P}<0.01)$.

\section{Freedom from Recurrent $A F$}

After a mean follow-up of $199 \pm 35$ days, 18 (82\%) of the 22 patients with paroxysmal $\mathrm{AF}$ were free from recurrent episodes of AF in the absence of any antiarrhythmic drug therapy.

\section{Discussion}

\section{Main Findings}

The main findings of this study are as follows. (1) There are intermittent bursts of rapid electrical activity in the CS during $\mathrm{AF}$ that have a shorter cycle length than in the adjacent left atrium. (2) Electrical connections between the CS and the left atrium can be identified by conventional mapping techniques and reliably ablated. (3) Electrical disconnection of the CS from the left atrium reduces the likelihood of inducing sustained AF in patients who still have inducible sustained AF after pulmonary vein isolation. (4) Electrical disconnection of the CS form the left atrium in conjunction with pulmonary vein isolation results in freedom from recurrent episodes of $\mathrm{AF}$ in $\sim 80 \%$ of patients with paroxysmal AF.

These findings suggest that rapid repetitive electrical activity can occur within the muscle sleeve that surrounds the $\mathrm{CS}$ and may contribute to the maintenance of AF.

\section{Role of the CS in AF}

Bursts of rapid electrical activity were found to alternate between the left atrium and the CS up to 20 times per minute during AF. The observation that the cycle length at times was shorter in the CS than in the adjacent left atrium suggests that the bursts of rapid electrical activity were generated in the CS, as opposed to simply reflecting the electrical activity in the adjacent left atrium.

After electrical disconnection of the CS from the left atrium, sustained AF was inducible much less often than before disconnection. This suggests that the rapid electrical activity that originates in the muscular sleeves of the CS may play a role in the maintenance of AF. Of note is that intermittent bursts of rapid activity arising in the pulmonary veins previously have been demonstrated to play a role in perpetuating $\mathrm{AF}^{1,2}$ The results of the present study suggest that the CS may function to maintain $\mathrm{AF}$ in the same manner as the pulmonary veins.

\section{Mechanism of Rapid Electrical Activity Arising in the CS}

Focal atrial tachycardias probably caused by abnormal automaticity or triggered activity can originate in the CS musculature. ${ }^{7,8}$ Furthermore, the complex spatial orientation of muscular fibers around the CS and their discrete insertion points in the left atrium may facilitate reentry within the CS. $^{5,18}$

Abnormal automaticity with the CS musculature might be expected to persist even after electrical disconnection of the CS. Therefore, because the bursts of rapid electrical activity became less frequent and slower after electrical disconnection of the CS from the left atrium, abnormal automaticity is unlikely to be the mechanism of the rapid electrical activity. 

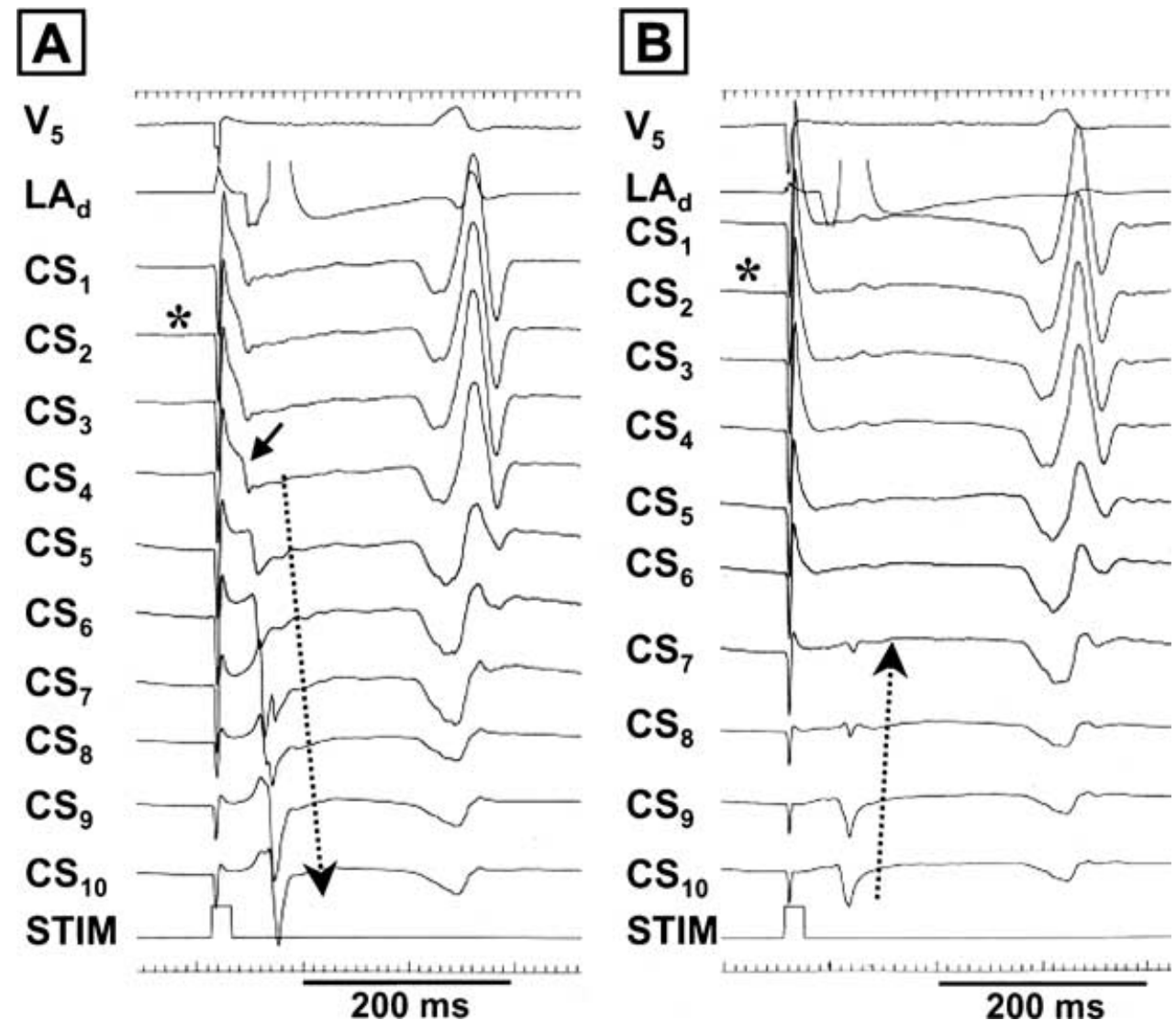

Figure 5. Example of ablation of an electrical connection between the coronary sinus (CS) and the left atrium. Shown are unipolar recordings from a decapolar catheter positioned within the CS. A: Preablation, during pacing at the posterior mitral valve annulus adjacent to electrode 2 (asterisk), the earliest CS potential was recorded at CS (arrow), indicating the presence of an electrical connection between the left atrium and CS at this site. B: After applications of radiofrequency energy at the inferior mitral valve annulus adjacent to electrodes 4 and 7, a CS potential was no longer present at electrodes 1-6 of the decapolar catheter and was still present at electrodes 7-10, which were closest to the ostium. In addition, the activation sequence (dashed line) within the CS during pacing adjacent to $\mathrm{CS}_{4}$ changed, with the site of earliest CS activation shifting from $\mathrm{CS}_{4}$ to $\mathrm{CS}_{10}$. The shift in activation sequence within the CS reflects activation of the CS musculature only from the right atrium, consistent with electrical disconnection of the CS from the left atrium. Abbreviations as in Figure 2.

As is the case with the muscle sleeves surrounding the pulmonary veins,${ }^{19,20}$ rapid electrical activity within the CS may be more likely to be caused by reentry or triggered activity in response to the rapid stimulation that occurs during $\mathrm{AF}$ or rapid atrial pacing. However, the mechanism of the rapid activity arising in the CS remains to be determined.

\section{Electrical Connections Between CS and Left Atrium}

The sites of electrical connections between the CS and the left atrium were identified by the activation sequence of unipolar electrograms recorded within the CS during pacing at different sites along the mitral annulus. A change in CS activation sequence after ablation confirmed that the presumptive sites of electrical connections had been correctly identified.

In a prior study, sites of electrical connections were identified by the analysis of double potentials during pacing from the proximal and distal CS and introduction of a premature stimulus. ${ }^{18}$ However, in contrast to the present study, ablation was not performed in the prior study and, therefore, no validation of the results of the electrogram analysis was available.

\section{Electrical Disconnection of the CS}

In the present study, electrical disconnection of the CS from the left atrium was achieved by radiofrequency ablation along the endocardial atrial aspect of the mitral annulus. The electrical connections between the CS and the left atrium also might be ablated by applications of radiofrequency energy within the CS. However, this approach to ablation might be associated with a greater risk of perforation of the CS or injury to the coronary arteries. Furthermore, it may be easier to achieve effective disconnection by targeting the thinnedout muscular extensions of the CS on the left atrial side of the annulus. ${ }^{21}$

In the present study, the CS was electrically isolated from the left atrium, but no attempts were made to isolate the CS from the right atrium. Nevertheless, sustained AF usually was rendered noninducible. This is consistent with the results of prior studies that have indicated that the left atrium plays a more important role than the right atrium in generating $\mathrm{AF}^{22-27}$

Applications of radiofrequency energy at the mitral valve annulus often resulted in the loss of CS potentials within the CS. In addition, the stimulus to CS potential interval lengthened significantly after ablation of the connections between 

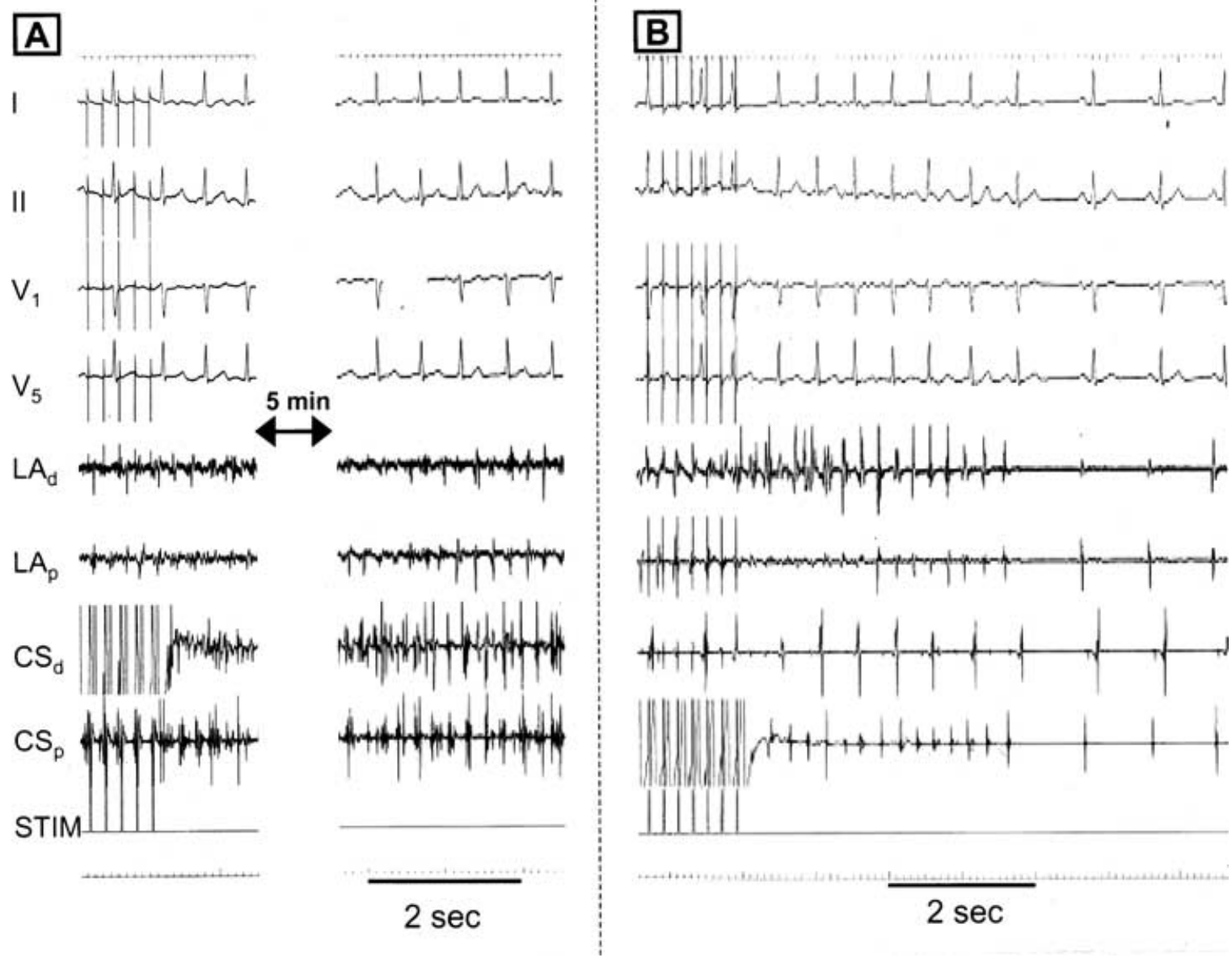

Figure 6. Effect of electrical disconnection of the coronary sinus (CS) from the left atrium (LA) on inducibility of atrial fibrillation (AF). A: After isolation of the pulmonary veins, AF that persisted for more than 5 minutes was still inducible by atrial pacing at a cycle length of 180 ms. The mean cycle length within the CS was $105 \mathrm{~ms}$. B: After electrical disconnection of the CS from the LA, sustained AF was no longer inducible. The induced AF lasted only 4 seconds, and the mean cycle length was $285 \mathrm{~ms}$.

the left atrium and CS. These effects of ablation on the CS potentials may have resulted from direct damage to the muscle fibers within the CS. In addition, similar to the muscle sleeves surrounding the pulmonary veins,$^{28}$ the electrical activity of the muscle fibers within the CS may be dependent on electrical input from the left or right atrium, and once this input is eliminated, they may become electrically silent. It also is possible that the muscle fibers surrounding the CS are electrically insulated from each other, ${ }^{28}$ such that electrical disconnection of the CS results in elimination of CS potentials within a segment of the CS, while other segments may still have residual potentials. In this study, $\sim 50 \%$ of all residual CS potentials were located near the CS ostium, consistent with input to the CS only from the right atrium.

\section{Prior Studies}

In a prior report of patients with valvular heart disease and $\mathrm{AF}$, earliest activation during reinitiation of $\mathrm{AF}$ was found to occur around the ostium of the CS, and radiofrequency energy applications at the ostium resulted in the noninducibility of $\mathrm{AF}^{29}$ Therefore, in the present study, it is possible that connections between the CS and the right atrium were responsible for the episodes of sustained AF that were still inducible in 3 of 9 patients despite disconnection of the CS from the left atrium. In addition, other sources such as the left atrium itself, the superior vena cava, the ligament of Marshall, or the crista terminalis may have contributed to the persisting inducibility of $\mathrm{AF}$ in these patients.

\section{Role of the CS in Global Atrial Activation}

Previous studies have shown that the muscular sleeve of the CS serves as a major electrical connection between the left and right atria. ${ }^{30,31}$ However, this is the first study to demonstrate that electrical disconnection of the CS from the left atrium results in prolongation of the $\mathrm{P}$ wave duration. Although it is possible that a conduction delay within the left or right atrium may result in prolongation of the $\mathrm{P}$ wave, the increase in $\mathrm{P}$ wave duration immediately after electrical disconnection, without any interventions in the atria, suggests that the interatrial conduction time lengthened. The $\mathrm{P}$ wave duration increased by only approximately $10 \%$, perhaps because of persistent conduction through Bachmann's bundle and other interatrial connections..$^{30,31}$

\section{Study Limitations}

A limitation of this study is that CS angiography was not routinely performed to define the anatomy of the CS and its branches. Therefore, the location of the CS to left atrial connections relative to landmarks such as the vein of Marshall cannot be specified. 


\section{Conclusion}

The aim of the present study was to determine the feasibility of CS disconnection from the left atrium and its acute effect on the inducibility of AF. The study demonstrates that CS disconnection from the left atrium is feasible in a practical fashion and that the inducibility of AF lasting more than 5 minutes after pulmonary vein isolation is markedly attenuated by electrical disconnection of CS from the left atrium. A prior study demonstrated that the noninducibility of $\mathrm{AF}$ lasting more than 5 minutes after ablation was predictive of a successful clinical outcome in patients who underwent pulmonary vein isolation because of drug-refractory AF. ${ }^{1}$ This provides a basis for concluding that the noninducibility of AF lasting more than 5 minutes after electrical disconnection of the CS from the left atrium also may have clinical significance.

The results of this study suggest that the CS may function as a fifth pulmonary vein in the maintenance of $\mathrm{AF}$, perhaps accounting for recurrent $\mathrm{AF}$ in at least some of the $15 \%$ to $40 \%$ of patients who fail to respond to pulmonary vein isolation. ${ }^{11,12,27}$ However, a larger-scale study comparing outcomes in patients who undergo pulmonary vein isolation with and without electrical disconnection of the CS is needed to establish the clinical value of CS disconnection.

\section{References}

1. Oral H, Ozaydin M, Tada H, Chugh A, Scharf C, Hassan S, Lai S, Greenstein R, Pelosi F Jr, Knight BP, Strickberger SA, Morady F: Mechanistic significance of intermittent pulmonary vein tachycardia in patients with atrial fibrillation. J Cardiovasc Electrophysiol 2002;13:645-650.

2. Oral H, Knight BP, Ozaydin M, Chugh A, Lai SW, Scharf C, Hassan S, Greenstein R, Han JD, Pelosi F Jr, Strickberger SA, Morady F: Segmental ostial ablation to isolate the pulmonary veins during atrial fibrillation: Feasibility and mechanistic insights. Circulation 2002;106:1256-1262.

3. Maros TN, Racz L, Plugor S, Maros TG: Contributions to the morphology of the human coronary sinus. Anat Anz 1983;154:133-144.

4. Antz M, Otomo K, Arruda M, Scherlag BJ, Pitha J, Tondo C, Lazzara R, Jackman WM: Electrical conduction between the right atrium and the left atrium via the musculature of the coronary sinus. Circulation 1998;98:1790-1795.

5. Ho SY, Sanchez-Quintana D, Cabrera JA, Anderson RH: Anatomy of the left atrium: implications for radiofrequency ablation of atrial fibrillation. J Cardiovasc Electrophysiol 1999;10:1525-1533.

6. Chauvin M, Shah DC, Haissaguerre M, Marcellin L, Brechenmacher C: The anatomic basis of connections between the coronary sinus musculature and the left atrium in humans. Circulation 2000;101:647-652.

7. Volkmer M, Antz M, Hebe J, Kuck KH: Focal atrial tachycardia originating from the musculature of the coronary sinus. J Cardiovasc Electrophysiol 2002;13:68-71.

8. Eckardt L: Automaticity in the coronary sinus. J Cardiovasc Electrophysiol 2002;13:288-289.

9. Olgin JE, Jayachandran JV, Engelstein E, Groh W, Zipes DP: Atrial macroreentry involving the myocardium of the coronary sinus: A unique mechanism for atypical flutter. J Cardiovasc Electrophysiol 1998;9:1094-1099.

10. Katritsis D, Ioannidis JP, Giazitzoglou E, Korovesis S, Anagnostopoulos $\mathrm{CE}, \mathrm{Camm}$ AJ: Conduction delay within the coronary sinus in humans. J Cardiovasc Electrophysiol 2002;13:859-862.

11. Haissaguerre M, Shah DC, Jais P, Hocini M, Yamane T, Deisenhofer I, Chauvin M, Garrigue S, Clementy J: Electrophysiological breakthroughs from the left atrium to the pulmonary veins. Circulation 2000;102:2463-2465.

12. Oral H, Knight BP, Tada H, Ozaydin M, Chugh A, Hassan S, Scharf C, Lai SW, Greenstein R, Pelosi F Jr, Strickberger SA, Morady F: Pulmonary vein isolation for paroxysmal and persistent atrial fibrillation. Circulation 2002;105:1077-1081.

13. Cosio FG, Anderson RH, Kuck KH, Becker A, Borggrefe M, Campbell RW, Gaita F, Guiraudon GM, Haissaguerre M, Rufilanchas JJ, Thiene G,
Wellens HJ, Langberg J, Benditt DG, Bharati S, Klein G, Marchlinski F, Saksena S: Living anatomy of the atrioventricular junctions. A guide to electrophysiologic mapping. A Consensus Statement from the Cardiac Nomenclature Study Group, Working Group of Arrhythmias, European Society of Cardiology, and the Task Force on Cardiac Nomenclature from NASPE. Circulation 1999;100:e31-e37.

14. Cook AC, Anderson RH: Attitudinally correct nomenclature. Heart 2002;87:503-506.

15. Kumagai K, Yasuda T, Tojo H, Noguchi H, Matsumoto N, Nakashima $\mathrm{H}$, Gondo N, Saku K: Role of rapid focal activation in the maintenance of atrial fibrillation originating from the pulmonary veins. Pacing Clin Electrophysiol 2000;23:1823-1827.

16. Wu TJ, Ong JJ, Chang CM, Doshi RN, Yashima M, Huang HL, Fishbein MC, Ting CT, Karagueuzian HS, Chen PS: Pulmonary veins and ligament of Marshall as sources of rapid activations in a canine model of sustained atrial fibrillation. Circulation 2001;103:1157-1163.

17. O'Donnell D, Furniss SS, Bourke JP: Paroxysmal cycle length shortening in the pulmonary veins during atrial fibrillation correlates with arrhythmogenic triggering foci in sinus rhythm. J Cardiovasc Electrophysiol 2002;13:124-128.

18. Kasai A, Anselme F, Saoudi N: Myocardial connections between left atrial myocardium and coronary sinus musculature in man. J Cardiovasc Electrophysiol 2001;12:981-985.

19. Chen YJ, Chen SA, Chen YC, Yeh HI, Chan P, Chang MS, Lin CI: Effects of rapid atrial pacing on the arrhythmogenic activity of single cardiomyocytes from pulmonary veins: Implication in initiation of atrial fibrillation. Circulation 2001;104:2849-2854.

20. Jais P, Hocini M, Macle L, Choi KJ, Deisenhofer I, Weerasooriya R, Shah DC, Garrigue S, Raybaud F, Scavee C, Le Metayer P, Clementy J, Haissaguerre M: Distinctive electrophysiological properties of pulmonary veins in patients with atrial fibrillation. Circulation 2002;106:2479-2485.

21. Ho SY, Anderson RH, Sanchez-Quintana D: Atrial structure and fibres: Morphologic bases of atrial conduction. Cardiovasc Res 2002;54:325336.

22. Cox JL, Schuessler RB, Lappas DG, Boineau JP: An 8 1/2-year clinical experience with surgery for atrial fibrillation. Ann Surg 1996;224:267273; discussion 273-275.

23. Cox JL, Ad N: New surgical and catheter-based modifications of the Maze procedure. Semin Thorac Cardiovasc Surg 2000;12:68-73.

24. Mohr FW, Fabricius AM, Falk V, Autschbach R, Doll N, Von Oppell U, Diegeler A, Kottkamp H, Hindricks G: Curative treatment of atrial fibrillation with intraoperative radiofrequency ablation: Short-term and midterm results. J Thorac Cardiovasc Surg 2002;123:919-927.

25. Pappone C, Oreto G, Lamberti F, Vicedomini G, Loricchio ML, Shpun S, Rillo M, Calabro MP, Conversano A, Ben-Haim SA, Cappato R, Chierchia S: Catheter ablation of paroxysmal atrial fibrillation using a 3D mapping system. Circulation 1999;100:1203-1208.

26. Pappone C, Rosanio S, Oreto G, Tocchi M, Gugliotta F, Vicedomini G, Salvati A, Dicandia C, Mazzone P, Santinelli V, Gulletta S, Chierchia S: Circumferential radiofrequency ablation of pulmonary vein ostia: A new anatomic approach for curing atrial fibrillation. Circulation 2000;102:2619-2628.

27. Pappone C, Oreto G, Rosanio S, Vicedomini G, Tocchi M, Gugliotta F, Salvati A, Dicandia C, Calabro MP, Mazzone P, Ficarra E, Di Gioia C, Gulletta S, Nardi S, Santinelli V, Benussi S, Alfieri O: Atrial electroanatomic remodeling after circumferential radiofrequency pulmonary vein ablation: Efficacy of an anatomic approach in a large cohort of patients with atrial fibrillation. Circulation 2001;104:2539-2544.

28. Oral H, Knight BP, Tada H, Morady F: Tachycardia and bradycardia coexisting in the same pulmonary vein. J Cardiovasc Electrophysiol 2002;13:186-188.

29. Nair M, Shah P, Batra R, Kumar M, Mohan J, Kaul U, Arora R: Chronic atrial fibrillation in patients with rheumatic heart disease: Mapping and radiofrequency ablation of flutter circuits seen at initiation after cardioversion. Circulation 2001;104:802-809.

30. Roithinger FX, Cheng J, SippensGroenewegen A, Lee RJ, Saxon LA, Scheinman MM, Lesh MD: Use of electroanatomic mapping to delineate transseptal atrial conduction in humans. Circulation 1999;100:17911797.

31. Calo L, Lamberti F, Loricchio ML, Castro A, Boggi A, Colivicchi F, Pandozi C, Santini M: Transseptal activation during left atrial pacing in humans: Electroanatomic mapping using a noncontact catheter and the intracardiac echocardiography. J Interv Card Electrophysiol 2002;6:149-159. 